\title{
Effect of pregnancy on breast and cervical carcinogenesis, the two most common female
}

\section{cancers}

\begin{abstract}
Statistical reports have shown that breast and cervical malignancies are the most frequent cancers found in the general female population. As more women choose to delay childbearing, the frequency of associated breast cancer is increasing and it is now the most common pregnancy associated carcinoma. The influence of pregnancy on the risk of breast cancer is dependent on several maternal features related to reproductive, genetic and hormonal factors. The effects of pregnancy on the course of breast cancer and its prognosis are complex. It is known that breast cancer is more aggressive in younger women, but whether it is more aggressive during pregnancy in these same women is debatable. One of the reasons for which overall prognosis is diminished in pregnant women is because breast cancer is usually diagnosed at more advanced stage during pregnancy. Ranked second as the most common malignancy in the female population, after breast carcinoma, cancer of the cervix, where HPV (Human papillomavirus) infection is a necessary cause, has a high incidence of $8.9 \%$ in all races and a death rate of $2.8 \%$. It is the second cause of cancer death in females aged between 20 and 39 years and it is now known that pregnancy can play an important role in cervical carcinogenesis as well. The aim of this review is to see how the hormonal changes occurring during pregnancy increases the risk of both breast and cervical cancers.
\end{abstract}

Keywords: pregnancy, breast cancer, cervical cancer, estrogen, progesterone
Volume 2 Issue 3 - 2017

\author{
Preetam Kona Herkanaidu,' Purnima Mohur, ${ }^{2}$ \\ Jyoti Ramudu ${ }^{2}$ \\ 'Department of Obstetrics and Gynecology, Nanjing Medical \\ University, China \\ ${ }^{2}$ Department of Obstetrics and Gynecology, University of \\ Mauritius, Mauritius
}

\begin{abstract}
Correspondence: Preetam Kona Herkanaidu, Department of Obstetrics and Gynecology Nanjing Medical University, Jiangsu Province, Nanjing, China, Tel +86- I58-05 I5-3049,
\end{abstract} Email pkherkanaidu@yahoo.com

Received: April 25, 2017| Published: May 02, 2017
Abbreviations: $\mathrm{PABC}$, pregnancy associated breast cancer; $\mathrm{CC}$, cervical cancer; HCG, human chorionic gonadotropin; BCAR, breast cancer antiestrogen resistance; PR, progesterone receptor; TZ, transformation zone; DC, dendrites' cell; TC, langerhans cells; LCR, long control region

\section{Introduction}

Pregnancy-associated breast cancer (PABC) is defined as any breast malignancy diagnosed during pregnancy or up to one year postpartum. ${ }^{1}$ The incidence of PABC is increasing ${ }^{2}$ and at a reported range of $1: 3,000$ to $1: 10,000$ pregnancies ${ }^{3-7}$ it is presently the most frequently diagnosed type of cancer during pregnancy. ${ }^{8}$ The average age of women with PABC is between 32 and 38years. ${ }^{5,9,10}$ The diagnosis of PABC is expected to become more frequent, since the percentage of women aged $35 y$ years and over at first birth has increased, underscoring the increasing trend for women to delay childbearing. ${ }^{3,6,7,11}$ It is noted that breast cancer diagnosed within 5years postpartum has a 2.8 times higher risk for metastasis and 2.7times higher mortality risk than that in nulliparous women. ${ }^{12,13}$ The mechanisms that make pregnancy a poor prognostic factor remain unclear; while some suggest that this may be associated with the hormonal changes physiological to pregnancy ${ }^{14}$ which possibly increases breast cancer aggressiveness, ${ }^{15}$ others think that this may be due to the fact that breast cancer is diagnosed at a more advanced stage in pregnancy. ${ }^{16}$ Along with the increased incidence of $\mathrm{PABC}$, and ranked first as the most common reproductive tract malignancy associated with pregnancy, ${ }^{17-19}$ stage 1 cervical cancer is 3times more likely to be diagnosed in pregnant women than in their non-pregnant matched controls. ${ }^{20}$ Based on their association with cervical cancer (CC), HPV genotypes are classified as low-risk or high-risk ${ }^{21}$ and it is known that persistent infection with high-risk HPV genotypes is a necessary although not sufficient cause of CC..$^{22}$ The involvement of other factors, in addition to HPV, is therefore needed to induce cervical carcinogenesis and immune deficiency favors viral persistence and cervical cancer. ${ }^{23,24}$ Pregnancy can hasten and aggravate infection by high risk HPV (in particular, by HPV 16) and presents highly suitable conditions for HPV activation, persistence and transformation. ${ }^{25}$

\section{The effect of gestational hormones on breast carcino- genesis}

Pregnancy has a double effect on breast cancer; an immediate increase in risk after childbirth followed by long-term protection, ${ }^{26}$ which becomes apparent after the age of 40 years. ${ }^{27}$ Both pregnancy and breast cancer are hormone dependent conditions which are under direct influence of estrogen, progesterone and human chorionic gonadotropin (hCG) $)^{28}$ Both hormonal and non-hormonal mechanisms have been suggested to explain the adverse effect of pregnancy on breast cancer risk. ${ }^{29}$ The hormonal factors associated with pregnancy play a complex role in the occurrence of PABC along with a specific genetic background. ${ }^{30}$ It is suspected that PABC prevalence might be higher in BRCA1 mutation carriers than in BRCA2 mutation. ${ }^{16,31}$ BRCA1 expression is induced during puberty and pregnancy and is believed to promote differentiation. Loss of BRCA1 nuclear expression is suggested to be involved in the development of breast cancer. ${ }^{32}$ Litwiniuk and colleagues proved that BRCA1 mutation carriers are more likely to have estrogen receptor ER $\alpha(-)$ breast cancer, while the expression of ER $\beta$ protein was observed in $42 \%$ of BRCA1-related tumors. ${ }^{33}$ The role of breast cancer antiestrogen 
resistance 4 (BCAR4) is an example of how the genetic environment is involved in breast cancer. BCAR4 is a powerful transforming gene causing estrogen-independent growth and antiestrogen resistance, and enhances tumor formation in vivo. It is found in $27 \%$ of primary breast tumors and while it is highly expressed in human placenta and oocytes, it is absent in other normal tissues. Birth characteristics, namely gestational age and birth length, are associated with maternal hormone levels and hormonal exposure in uterus, which increases the risk of breast cancer in adulthood. This exposure has a stronger effect in early breast cancers. ${ }^{34}$ Ovarian hormones, that are the female sex steroid hormones, are major risk factors for breast cancer initiation and progression. ${ }^{35}$ Circulating levels of estrogen, progesterone and prolactin, a potent mitogen for breast cancer cells, are at their peak during pregnancy and lactation. These hormones are strong modulators of mammary epithelial cell proliferation and the accelerated breast tumor growth during pregnancy and lactation could be associated to differences in systemic hormone levels secreted during pregnancy, the immune suppressive effects of pregnancy and breast involution after pregnancy. ${ }^{36,37}$ As breast cancer is a hormone dependent entity, the effect of the elevated maternal sex-steroid hormones on cancer cell proliferation possibly explains the transient increased risk of PABC. Normally, breast cancer cells which express ER multiply faster in response to these gestational hormones. Since PABC tumors lack ER/ PR (progesterone receptor) expression, estrogen or progesterone are thought to be involved in PABC by indirect binding to related receptors expressed by breast epithelial cells..$^{27,30,31,38}$ The exact mechanisms for this is still unclear but it is estimated that direct tumor-initiating effects occur through the induction of enzymes and proteins involved in nucleic acid synthesis and through the activation of certain oncogenes. In addition, the stimulation of prolactin secretion and the production of growth factors and non-growth factor peptides are part of the indirect effects. The risk of breast cancer could be determined by the cumulative exposure of breast tissue to estrogen..$^{39}$ Lukanova and colleagues showed that concentrations of estrogens during the early stage of a primiparous pregnancy are associated with maternal risk of breast cancer and this effect may vary with age. Estradiol concentration was shown to be associated positively with the risk of breast cancer before age of 40years. ${ }^{27}$

In their study with TA2 mice, Wang and colleagues showed that the concentration of estradiol and progesterone were significantly elevated during pregnancy and slightly increased after delivery with the increase of gravidity. The same pattern was also observed for immunosuppressant. Both of these factors are partially responsible for the presence of abnormally proliferating epithelia and the escape of tumor cells from immune surveillance.$^{30}$ Moreover, alterations in tissue-specific promoters of aromatase gene expression also lead to variations in estrogen production. As a result, the aromatase gene may act as an oncogene that initiates tumor formation in breast tissue. ${ }^{39}$

\section{How the hormonal changes during pregnancy favor cervical carcinogenesis}

As per their association with cervical cancer (CC), HPV genotypes are classified as low-risk or high-risk. ${ }^{40}$ High-risk (HPV) is a small DNA tumor virus that infects the mucosal squamous epithelium and causes various malignant diseases in humans, with cancer of the cervix being one among them. ${ }^{41}$ HPV dependent carcinogenesis starts with the infection of HPV in episomal form which initiates the transcription of viral gene products. This is followed by subsequent genomic integration of HPV oncogenes into the host genome. ${ }^{42}$ Pregnancy can hasten and aggravate infection by high-risk HPV (in particular, by HPV 16) and presents highly suitable conditions for HPV activation, persistence and transformation. ${ }^{43}$ This can be explained by the raised levels of estrogen and progesterone during pregnancy which brings the following changes.

The vaginal flora specifically presents an imbalance that favors the development of infectious agents, including HPV. During pregnancy, there occur anatomical modifications of the genital tract such as increased hypertrophy and congestion of the cervix followed by metaphase. The transformation zone is maintained (TZ) on the exo-cervix (ectopic) for many years following pregnancy as a result of which this area of immature squamous metaphase becomes more susceptible to the development of HPV infections and pre-neoplastic lesions. ${ }^{44}$ Under the influence of these hormones, the local immune microenvironment of the cervix is altered and this sensitizes the $\mathrm{TZ}$ to cervical cancer formation. The squamous epithelium of the cervix is composed of keratinocytes, which are the primary targets of HPV, and a type of immature dendrites' cell (DC), the Langerhans cells (LC), which are important for the immuno-surveillance of the squamous epithelium. ${ }^{45}$ Estradiol and progesterone influence the APC (antigen-presenting cell) functions of DC, with estradiol generally suppressing APC function. ${ }^{46}$ Moreover, in the transformation zone, estradiol has a high rate of conversion to 16a-hydroxyestrone ${ }^{47,48}$ which covalently binds and activates ER $\alpha$. ER $\alpha$ is necessary for the genesis and continued growth of cancer and its expression in stoma cells is essential for disease progression. ${ }^{49-51}$ It is hypothesized that the activated ER $\alpha$ binds to responsive elements within the LCR (Long control region) and further induce E6 and E7 transcription to maintain HPV gene activity. ${ }^{49,52}$ Hence, it is postulated that both HPV and estradiol enhance the effects of each other, either directly through functional EREs (Estrogen responsive elements) in the viral genome or indirectly encourage uncontrolled cellular proliferation and enhancing malignant proliferation. ${ }^{53}$ This synergistic combination between estrogen and HPV is considered as the strongest factor in such carcinogenic transformations. ${ }^{50,54-57}$

Furthermore, estrogen is known to have a mutagenic activity which can be amplified by viral oncogenes ${ }^{58}$ It stimulates the proliferation of human keratinocytes by promoting the expression of cyclin D2 and inducing $\mathrm{G} 1$ to $\mathrm{S}$ phase progression in the cell cycle. ${ }^{59}$ Estrogen also inhibits the oxidative stress-induced apoptosis in keratinocytes and promotes expression of the anti-apoptotic protein bcl-2. ${ }^{60}$ It can also induce direct DNA damage via its catechol metabolites ${ }^{61}$ and HPV infection has shown to considerably increase the formation of these potentially carcinogenic estrogen metabolites. ${ }^{48}$ Moreover, it is known that estrogen has the property to influence the immune system by acting on the cytokine production. ${ }^{62}$ Estradiol has been shown to inhibit the expression of GM-CSF in the U2OS cell line via its interaction with $\mathrm{ER} \alpha$ and to decrease this production via contact with ER $\beta .^{63}$

Along with estrogen, progesterone also acts on cytokine production to affect the immune system. ${ }^{63}$ It increases the production of $\mathrm{IkB} \alpha$, an inhibitor of $\mathrm{NFkB}^{64}$ and has an inhibitory effect on GMCSF secretion. ${ }^{65}$ The immunosuppression caused mainly by the elevated progesterone, which is fundamental for maintaining a fetus during pregnancy, predisposes a woman further to the acquisition and development of lesions by HPV. ${ }^{44,45,66}$ Researches in molecular biology have also found an interaction between progesterone and HPV and it is now known that HPV 16 encodes a protein located 
in the region of E6 and E7 reading frames that joins with activated ras oncogenes to transform primary cells. ${ }^{67}$ The LCR of HPV16 is reported to contain a deoxyribonucleic acid sequence that enhances response to both progesterone and glucocorticoids thereby increasing E6 and E7 transcription. ${ }^{68}$ E6 and E7 oncoproteins bind to p53 and $\mathrm{Rb}$, respectively, and surpass the host defense system. ${ }^{69-71}$ In pregnancy, the increased circulating progesterone level enhances HPV gene expression, giving rise to larger numbers of viral copy and multiplication of virus-transformed cells. ${ }^{72}$ During the first trimester, the immune response to HPV is low and this accounts for the higher frequency of persistence of the virus. ${ }^{73}$

In addition, HPV DNA is often integrated into the host genome and leads to the loss of E2 gene which is a modulator of HPV gene expression and induces apoptosis. ${ }^{74}$ It was found that E2 and E7 proteins can induce apoptosis in transformed cells $\mathrm{s}^{75}$ and that progesterone and estrogen increase the levels of E2 and E7-induced apoptosis. ${ }^{76}$ However, with the loss of E2 in HPV infection, cell proliferation might increase. ${ }^{74}$ Also, in the absence of E2, these hormones have been found to be a possible risk factor for cervical carcinogenesis via their effects on HPV gene expression. ${ }^{77}$

\section{Conclusion}

The increased incidence of breast and cervical cancers during pregnancy has enabled researchers to understand to some extent the mechanism through which the female sex steroid hormones act in causing these cancers. However, further knowledge about the interaction between these malignancies and the gestational hormones, at molecular level, are required before new medical therapies can be developed for managing these cancers efficiently.

\section{Acknowledgements}

None.

\section{Conflict of interest}

Author declares that there is no conflict of interest.

\section{References}

1. Buré LA, Azoulay L, Benjamin A, et al. Pregnancy-Associated Breast Cancer: A Review for the Obstetrical Care Provider. J Obstet Gynaecol Can. 2011;33(4):330-337.

2. Borges VF, Schedin PJ. Pregnancy-associated breast cancer: an entity needing refinement of the definition. Cancer. 2011;118(3):3226-3228.

3. Amant F, Loibl S, Neven P, et al. Breast cancer in pregnancy. Lancet. 2012;379(9815):570-579.

4. Andersson TM, Johansson AL, Hsieh CC, et al. Increasing incidence of pregnancy-associated breast cancer in Sweden. Obstet Gynecol. 2009;114(3):568-572.

5. Navrozoglou I, Vrekoussis T, Kontostolis E, et al. Breast cancer during pregnancy: A mini-review. Anticancer Res. 2007;34(8):837-843.

6. Lee Y, Roberts CL, Dobbins T, et al. Incidence and outcomes of pregnancy-associated cancer in Australia, 1994-2008: A population-based linkage study. BJOG. 2012;119(13):1572-1582.

7. Zagouri F, Psaltopoulou T, Dimitrakakis C, et al. Challenges in managing breast cancer during pregnancy. $J$ Thorac Dis. 2013;5(Suppl 1):S62-S67.
8. Smith LH, Danielsen B, Allen ME, et al. Cancer associated with obstetric delivery: results of linkage with the California cancer registry. Am J Obstet Gynecol. 2003;189(4):1128-1135.

9. Jacobs IA, Chang CK, Salti GI. Coexistence of pregnancy and cancer. Am Surg. 2004;70(11):1025-1029.

10. Molckovsky A, Madarnas Y. Breast cancer in pregnancy: a literature review. Breast Cancer Res Treat. 2008;108(3):333-338.

11. Azim Ha, Botteri $\mathrm{E}$, Renne $\mathrm{G}$, et al. The biological features and prognosis of breast cancer diagnosed during pregnancy: a case-control study. Acta Oncol. 2012;51(5):653-661.

12. Johansson AL, Andersson TM, Hsieh CC, et al. Stage at diagnosis and mortality in women with pregnancy-associated breast cancer (PABC) Breast Cancer Res Treat. 2013;139(1):183-192.

13. Callihan EB, Gao D, Jindal S, et al. Postpartum diagnosis demonstrates a high risk for metastasis and merits an expanded definition of pregnancy-associated breast cancer. Breast Cancer Res Treat. 2013;138(2):549-559.

14. Dimitrakakis C, Zagouri F, Tsigginou A, et al. Does pregnancy-associated breast cancer imply a worse prognosis? A matched case-case study. Breast Care (Basel). 2013;8(3):203-207.

15. Mathelin C, Annane K, Treisser A, et al. Pregnancy and post-partum breast cancer: a prospective study. Anticancer Res. 2008;28(4C):2447-2452.

16. Williams JW. Neoplastic Disorders. In: Cunningham FG, Leveno KJ, et al. editors. Williams Obstetrics. 24th ed. USA: McGraw-Hill Education; 2014. 1230p.

17. Palle C, Bangsboll S, Andreasson B. Cervical intraepithelial neoplasia in pregnancy. Acta Obstet Gynecol Scand. 2000;79(4):306-310.

18. Duggan B, Muderspach LI, Roman LD, et al. Cervical cancer in pregnancy: reporting on planned delay in therapy. Obstet Gynecol. 1993;82(4 pt 1):598-602.

19. Hacker NF, Berek JS, Lagasse LD. Carcinoma of the cervix associated with pregnancy. Obstet Gynecol. 1982;59(6):735-746.

20. Zemlickis D, Lishne M, Degendorfer P, et al. Maternal and fetal outcome after invasive cervical cancer in pregnancy. $J$ Clin Oncol. 1991;9(1):1956-1961.

21. Vincent C, Robert B, Kurt S, et al. Carcinogenicity of human papillomaviruses. Lancet Oncol. 2005;6(4):2042.

22. Munoz N, Castellsague X, Gonzalez AB, et al. Chapter 1: HPV in the etiology of human cancer. Vaccine. 2006;24 Suppl 3:S31-S310.

23. Song SH, Lee JK, Lee NW, et al. Interferon-gamma (IFN-gamma): a possible prognostic marker for clearance of high-risk human papillomavirus (HPV). Gynecol Oncol. 2008;108(3):543-548.

24. Einstein KH, Schiller JT, Viscidi RP, et al. Clinician's guide to human papillomavirus immunology: knowns and unknowns. Lancet Infect Dis. 2009;9(6):347-356.

25. Armbruster-Moraes E, Toshimoto LM, Leao E, et al. Prevalence of "high risk" human papillomavirus in the lower genital tract of Brazilian gravidas. Int J Gynaecol Obstet. 2000;69(3):223-227.

26. Kauppila A, Kyyrönen P, Hinkula M, et al. Birth intervals and breast cancer risk. Br J Cancer. 2009;101(7):1213-1217.

27. Lukanova A, Surcel HM, Lundin E, et al. Circulating estrogens and progesterone during primiparous pregnancies and risk of maternal breast cancer. Int J Cancer. 2012;130(4):910-920.

28. Santucci-Pereira J, George C, Armiss D, et al. Mimicking pregnancy as a strategy for breast cancer prevention. Breast Cancer Manag. 2013;2(4):283-294. 
29. Albrektsen G, Heuch I, Thoresen SØ. Histological type and grade of breast cancer tumors by parity, age at birth, and time since birth: A register-based study in Norway. BMC Cancer. 2010;10:226.

30. Chun Huang, Xuan Wang, Baocun Sun, et al. Study on mouse mode of triple-negative breast cancer: association between higher parity and triple-negative breast cancer. Targeted Oncology. 2015;10(1):85-97.

31. Yu JH, Kim MJ, Cho H, et al. Breast diseases during pregnancy and lactation. Obstet Gynecol Sci. 2013;56(3):143-159.

32. Reed W, Sandstad B, Holm R, et al. The prognostic impact of hormone receptors and c-erbB-2 in pregnancy-associated breast cancer and their correlation with BRCA1 and cell cycle modulators. Int J Surg Pathol. $2003 ; 11(2): 65-74$

33. Maria ML, Krzysztof R, Violetta F, et al. Expression of estrogen receptor beta in the breast carcinoma of BRCA1 mutation carriers. BMC Cancer 2008;8:100.

34. Pollán M. Epidemiology of breast cancer in young women. Breast Cancer Res Treat. 2010;123(Suppl 1):3-6.

35. Iversen A, Thune I, Mc Tiernan A, et al. Ovarian hormones and reproductive risk factors for breast cancer in premenopausal women: The Norwegian EBBA-I study. Hum Reprod. 2011;26(5):1519-1529.

36. Keyser EA, Staat BC, Fausett MB, et al. Pregnancy-associated breast cancer. Rev Obstet Gynecol. 2011;5(2):94-99.

37. McCready J, Arendt LM, Glover E, et al. Pregnancy-associated breas cancers are driven by differences in adipose stromal cells present during lactation. Breast Cancer Res. 2014;16(1):R2.

38. McCready J, Arendt LM, Rudnick JA, et al. The contribution of dynamic stromal remodeling during mammary development to breast carcinogenesis. Breast Cancer Res. 2010;12(3):205.

39. Clemons M, Goss P. Estrogen and the risk of breast cancer. $N$ Engl $J$ Med. 2001;344(4):276-285.

40. Cogliano V, Baan R, Straif K, et al. WHO International Agency for Research on Cancer. Carcinogenicity of human papillomaviruses. Lancet Oncol. 2005;6:2042.

41. Leemans CR, Braakhuis BJ, Brakenhoff RH. The molecular biology of head and neck cancer. Nat Rev Cancer. 2011;11(1):9-22.

42. Senapati R, Senapati NN, Dwibedi B. Molecular mechanisms of HPV mediated neoplastic progression. Infectious Agents and Cancer 2016;11:59.

43. Armbruster-Moraes E, Toshimoto LM, Leão E, et al. Prevalence of "high risk" human papillomavirus in the lower genital tract of Brazilian gravidas. Int J Gynaecol Obstet. 2000;69(3):223-227.

44. Correia HS, Cornetta MCM, Gonçalves AKS. Infecção genital pelopapilomavírushumano (HPV) emmulheresgrávidas. Rev Brasil de Genit 2000;1:14-19.

45. Romani N, Holzmann S, Tripp CH, et al. Langerhans cells-dendritic cells of the epidermis. APMIS. 2003;111(7-8):725-740.

46. Beagley KW, Gockel CM.Regulation of innate and adaptive immunity by the female sex hormones oestradiol and progesterone. FEMS Immunol Medi Microbiol. 2003;38(1):13-22.

47. Karen J Auborn, Craig Woodworth, Joseph A Dipaolo, et al. The interaction between HPV infection and estrogen metabolism in cervical carcinogenesis. Int J Cancer. 1991;49(6):867-869.

48. Matos A, Castelão C, Pereira da Silva A, et al. Epistatic interaction of CYP1A1 and COMT polymorphisms in cervical cancer. Oxidative Medicine and Cellular Longevity. 2016. 7p.
49. Chung SH, Wiedmeyer K, Shai A, et al. Requirement for estrogen receptor alpha in a mouse model for human papillomavirus-associated cervical cancer. Cancer Research. 2008;68(23):9928-9934.

50. Chung SH, Lambert PF. Prevention and treatment of cervical cancer in mice using estrogen receptor antagonists. Proc Natl Acad Sci USA. 2009;106(46):19467-19472.

51. Chung SH, Shin MK, Korach KS, et al. Requirement for stromal estrogen receptor alpha in cervical neoplasia. Horm Cancer. 2013;4(1):50-59.

52. Ethel Michel de Villiers. Relationship between steroid hormone contraceptives and HPV cervical intraepithelial neoplasia and cervical carcinoma. Int J Cancer. 2002;103(6):705-708.

53. Ramachandran B. Functional association of oestrogen receptors with HPV infection in cervical carcinogenesis. Endocrine-Related Cancer. 2017;24(4):R99-R108

54. Brake T, Lambert PF. Estrogen contributes to the onset persistence and malignant progression of cervical cancer in a human papillomavirus-transgenic mouse model. PNAS. 2005;102(7):2490--2495.

55. Marks M, Gravitt PE, Gupta SB, et al. The association of hormonal contraceptive use and HPV prevalence. International Journal of Cancer. 2011;128(12):2962-2970.

56. Marks MA, Gupta S, Liaw KL, et al. Prevalence and correlates of HPV among women attending family-planning clinics in Thailand. BMC Infec Dis. 2015;15: 159 .

57. Liao SF, Lee WC, Chen HC, et al. Baseline human papillomavirus infection high vaginal parity and their interaction on cervical cancer risks after a follow-up of more than 10 years. Cancer Causes and Control. 2012;23(5):703-708.

58. Liehr JG. Is estradiol a genotoxic mutagenic carcinogen? Endocr Rev 2000;21(1):40-54

59. Kanda N, Watanabe S. 17beta-estradiol stimulates the growth of human keratinocytes by inducing cyclin D2 expression. $J$ Invest Dermatol. 2004;123(2):319-328.

60. Kanda N, Watanabe S. 17beta-estradiol inhibits oxidative stress induced apoptosis in keratinocytes by promoting Bcl-2 expression. J Invest Dermatol. 2003;121(6):1500-1509.

61. Newfield L, Bradlow HL, Sepkovic DW, et al. Estrogen metabolism and the malignant potential of human papillomavirus immortalized keratinocytes. Proc Soc Expt Biol Med. 1998;217(3):322-326.

62. McMurray RW, Ndebele K, Hardy KJ, et al. 17-betaestradiol suppresses IL-2 and IL-2 receptor. Cytokine. 2001;14(6):324-333.

63. Brady H, Doubleday M, Gayo-Fung LM, et al. Differential response of estrogen receptors alpha and beta to SP500263, a novel potent selective estrogen receptor modulator. Mol Pharmacol. 2002;61(3):562-568.

64. Miller L, Hunt JS. Regulation of TNF-alpha production in activated mouse macrophages by progesterone. J Immunol. 1998;160(10):5098-5104.

65. Robertson SA, Mayrhofer G, Seamark RF. Ovarian steroid hormones regulate granulocyte-macrophage colony-stimulating factor synthesis by uterine epithelial cells in the mouse. Biol Reprod. 1996;54(1):183-196.

66. Rando RF, Lindheim S, Hasty L, et al. Increased frequency of detection of human papillomavirus deoxyribonucleic acid in exfoliated cervical cells during pregnancy. Am J Obstet Gynecol. 1989;161(1):50-55.

67. Matlaschewski G, Schneider J, Banks L, et al. Human papillomavirus type 16 DNA cooperates with activated ras oncogene in transforming primary cells. EMBO J. 1987;6(6):1741-1746. 
68. Crook T, Storey A, Almond N, et al. Human papillomavirus type 16 coorperates with activated ras and fos oncogenes in hormone dependent transformation of primary mouse cells. Proc Natl Acad Sci USA. 1988;85(23):8820-5524.

69. Moodley M, Moodley J, Chetty R, et al. The role of steroid contraceptive hormones in the pathogenesis of invasive cervical cancer: a review. Int $J$ Gynecol Cancer. 2003;13(2):103-110.

70. Sima N, Wang W, Kong D, et al. RNA interference against HPV16 E7 oncogene leads to viral E6 and E7 suppression in cervical cancer cells and apoptosis via upregulation of $\mathrm{Rb}$ and $\mathrm{p} 53$. Apoptosis. 2008;13(2):273-281.

71. Chung SH, Franceschi S, Lambert PF. Estrogen and ERalpha: culprits in cervical cancer? Trends in Endocrinology and Metabolism. 2010;21(8):504-511.

72. Chan WK, Klock G, Bernard HU. Progesterone and glucocorticoid response elements occur in the long control regions of several $\mathrm{Hu}$ man papillomaviruses involved in oncogenital neoplasia. $J$ Virol. 1989;63(8):3261-3269.
73. Chan WK, Klock G, Bernard HU. Progesterone and glucocorticoid response elements occur in the long control regions of several Human papillomaviruses involved in oncogenital neoplasia. J Virol. 1989;63:4417.

74. Webster K, Parish J, Pandya M, et al. The human papillomavirus (HPV) $16 \mathrm{E} 2$ protein induces apoptosis in the absence of other HPV proteins and via a p53-dependent pathway. J Biol Chem. 2000;275(1):87-94.

75. Demeret C, Garcia-Carranca A, Thierry F. Transcription-independent triggering of the extrinsic pathway of apoptosis by human papillomavirus 18 E2 protein. Oncogene. 2003;22(2):168-175.

76. Webster K, Taylor A, Gaston K. Oestrogen and progesterone increase the levels of apoptosis induced by the human papillomavirus type $16 \mathrm{E} 2$ and E7 proteins. J Gen Virol. 2001;82(pt 1):201-213.

77. Delvenne P, Herman L, Kholod N, et al. Role of hormone cofactors in the human papillomavirus-induced carcinogenesis of the uterine cervix. Mol Cellular Endocrinol. 2007;264(1-2):1-5. 